\title{
BACTÉRIAS PREDOMINANTES NA INFECÇÃO HOSPITALAR EM UTI PEDIÁTRICA: UMA REVISÃO INTEGRATIVE
}

\author{
Ana Carolina Meira Trindade ${ }^{1 *}$, Carolina Palmeira Teixeira Martins ${ }^{2}$, Mariane Costa Santos de \\ Tavares $^{3}$, Alexandre Guimarães Rodrigues ${ }^{4}$, Bianca Santos Pedrosa ${ }^{4}$, Emanuelle Almeida Silva \\ Viana4, Gabriela Machado Alves ${ }^{4}$, Gildemar Gonzaga Santos Júnior ${ }^{5}$, Moarah Gabrielly Souza \\ Brito $^{5}$, Rogério Benício de Almeida ${ }^{5}$ e Samara Guimarães Rodrigues ${ }^{6}$
}

${ }^{1}$ Autor Correspondente, Discente do Curso de Graduação de Medicina. Faculdade Santo Agostinho - FASA, Vitória da Conquista-Bahia. ${ }^{2}$ Docente do Curso de Graduação de Medicina. Faculdade Santo Agostinho - FASA,

Vitória da Conquista-Bahia. ${ }^{3}$ Fisioterapeuta. Pós-graduada em Terapia Intensiva. Discente do Curso de Graduação de Medicina. Faculdade Santo Agostinho - FASA, Vitória da Conquista - Bahia. ${ }^{4}$ Discente do Curso de Graduação de Medicina. Faculdade Santo Agostinho - FASA, Vitória da Conquista-Bahia. ${ }^{5}$ Discente do Curso de Graduação de Medicina. Faculdade de Medicina Santo Agostinho - FASA, Itabuna-Bahia. ${ }^{6}$ Discente do Curso de Graduação de Medicina. Universidade Vale do Rio Doce -UNIVALE, Valadares-Minas Gerais

\section{ARTICLE INFO}

\section{Article History:}

Received $17^{\text {th }}$ January, 2021

Received in revised form

$09^{\text {th }}$ February, 2021

Accepted $28^{\text {th }}$ March, 2021

Published online $13^{\text {th }}$ April, 2021

\section{Key Words:}

Infecção Hospitalar. Unidade de Terapia Intensiva Pediátrica. Bactérias. Bactérias Multirresistentes.

*Corresponding author:

Ana Carolina Meira Trindade

\begin{abstract}
Objetivo: Analisar as bactérias predominantes na infecção hospitalar e seus sítios mais prevalentes de contaminação na Unidade de Terapia Intensiva Pediátrica (UTIP). Métodos: Realiza-se, então, uma pesquisa bibliográfica do tipo revisão de literatura de caráter integrativo por meio de coleta de artigos científicos na língua portuguesa e inglesa referentes aos anos de 2015 a 2020, através das bases de dados, tais como Scielo, Pubmed e BVS. Além disso, em relação aos aspectos éticos serão mantidos todos os aspectos éticos para evitar plágio e cópias. Resultados: Seis artigos foram selecionados para análise e discussão dos dados, de acordo com os critérios de busca e inclusão identificados. Considerações finais: As bactérias mais predominantes nas UTIP são as bactérias gram-negativas multirresistente, associadas aos procedimentos invasivos, tempo de internamento e condições de saúde prévia do paciente.
\end{abstract}

Copyright $($ C) 2021, Ana Carolina Meira Trindade et al. This is an open access article distributed under the Creative Commons Attribution License, which permits unrestricted use, distribution, and reproduction in any medium, provided the original work is properly cited.

Citation: Ana Carolina Meira Trindade, Carolina Palmeira Teixeira Martins Mariane Costa Santos de Tavares et al. "Bactérias Predominantes na Infecção Hospitalar em UTI Pediátrica: uma revisão integrativa”, International Journal of Development Research, 11, (04), 45940-45945.

\section{INTRODUCTION}

A portaria $\mathrm{n}^{0} 3.432$ conceitua Unidade de Terapia Intensiva (UTI) como uma unidade hospitalar para atender pacientes graves ou de risco que precisam de assistência médica/ de enfermagem ininterrupta e especializada, com equipamentos específicos para diagnóstico e tratamento. A UTI pediátrica (UTIP) surge na década de 70 no Rio de Janeiro e São Paulo. Inclui paciente com idade de 29 dias a 14 ou 18 anos, a depender da instituição (ANVISA, 2010). As infecções surgem por falhas no sistema decorrentes da invasão, multiplicação e ação dos agentes infecciosos e de seus produtos tóxicos no hospedeiro, ocorrendo interação imunológica. As infecções hospitalares são aquelas que surgem após 72 horas de admissão hospitalar começando a manifestar durante a internação ou até 30 dias após a alta se ela estiver diretamente relacionada com a internação ou procedimento hospitalar (ANVISA, 2006). Aproximadamente ocorrem 15 mil óbitos infantis diariamente no planeta (UNICEF, 2016). As causas são fatores extrínsecos e intrínsecos que inclui - ser um extremo de idade, ter o sistema imune imaturo e ainda em formação e uma vulnerabilidade de sua anatomia e fisiologia (ANVISA, 2006). Em comparação aos pacientes que internam no hospital, $30 \%$ dos que vão para a UTI pediátrica desenvolvem infecção nosocomial, um aumento de 5 a 10 vezes (COSTA, ATTA, SILVIA, 2015). O tempo de internação é um fator que leva ao 
desenvolvimento de infecção hospitalar (IH) que por sua vez aumenta o tempo de permanência dos pacientes no hospital e favorece o surgimento de microrganismos multirresistentes. O período entre a admissão e primeira cultura positiva foi aproximadamente $12 \pm 9$ dias. Além disso, há uma prevalência de resistência antibiótica e complicações, principalmente nos casos em que a hemocultura demora a positivar. Esse aumento é responsável por maior morbidade e custos elevados nas internações em Unidade de Terapia Intensiva Pediátrica (UTIP) (JÚNIOR, 2012). O aumento das infecções bacterianas na UTIP, resistentes ou não, pode ser explicado, por exemplo, por lapso em técnicas de assepsia, maior número de procedimentos invasivos, escolha inadequada de antibióticos, doença de base grave e imunossupressão (ANVISA, 2006). A resistência das bactérias aos antibióticos pode ser inata ou adquirida e ocorre por três mecanismos básicos (RANG, et al, 2011): (1) Transferência de bactérias entre as pessoas; (2) Transferência dos genes da resistência entre as bactérias (pelos plasmídeos); (3) Transferência dos genes da resistência entre os elementos genéticos no interior da bactéria (os transpósons).

Os determinantes genéticos são: (1) mutações; (2) amplificação gênica; (3) determinantes extracromossômicos: os plasmídeos podem replicar-se independentemente e transportar os genes $r$ da resistência; (4) transpósons não podem autorreplicar, mas podem carrear um ou mais genes de resistência, é a integração de segmento de DNA de um plasmídeo para outro ou de um plasmídeo para um cromossomo, e vice-versa; (5) os processos de conjugação (transferência entre células do DNA cromossômico ou extracromossômico), transdução (DNA do plasmídeo sendo incorporado em um vírus bacteriano e transferido para outra bactéria da mesma espécie) e transformação (capta o DNA do meio ambiente e incorpora ao genoma por recombinação homóloga normal) (RANG, et al, 2011). Entre os determinantes bioquímicos de resistência aos antibióticos estão: (1) a produção de enzimas que inativam os beta-lactâmicos, cloranfenicol e aminoglicosídeos; (2) alteração do local sensível ao fármaco ou do ponto de ligação do fármaco; (3) redução da concentração do fármaco na bactéria; (4) alteração das vias enzimáticas (RANG, et al, 2011).

Um importante mecanismo de resistência bacteriana é a hidrolise do anel $\beta$-lactâmico do núcleo estrutural das penicilinas - o ácido 6aminopenicilâmico - que se torna o ácido penicilóico e seus derivados (ambos isentos de atividade antimicrobiana). Isso é feito pelas enzimas $\beta$-lactamases. O mecanismo é similar nas cefalosporinas e carbapenêmicos (TAVARES, 2001). Segundo Leoncio (2019) os custos por meio de um estudo feito em um hospital público no Paraná para pacientes que não precisaram de procedimentos ou cirurgias tiveram como mediana R\$ 7.048,60 já para os que precisaram foi $\mathrm{R} \$ 31.919,09$. Ou seja, há um aumento de 4,2 vezes mais sendo importante pesquisar o perfil epidemiológico das infecções bacterianas que mais acometem nas UTIP, visto que os custos para tratá-la representam uma parcela significativa dos gastos.

Esses tópicos levantam a importância de conhecer as bactérias predominantes de infecção hospitalar e seus sítios mais prevalentes de contaminação na UTIP. Tal estudo possibilita compreender algum dos motivos que favorecem a susceptibilidade do indivíduo a essas bactérias.

\section{MATERIAIS E MÉTODOS}

A metodologia do artigo é uma revisão integrativa da literatura. Para o levantamento dos artigos na literatura, realizou-se uma busca nas bases de dados da U.S. National Library of Medicina (Pubmed), Scientific Eletronic Library Online (SciELO) e da Biblioteca Virtual em Saúde (BVS). Os descritores em saúde utilizados foram Intensive Care Units, Pediatric AND bacterial AND Prevalence; Intensive Care Units, Pediatric AND bacterial AND Incidence para as plataformas BVS e PubMed e seus correspondentes em português para a plataforma Scielo. A busca dos artigos foi realizada on-line e a representação da sua inclusão está na Figura 1.
Os critérios de inclusão dos artigos foram: artigos completos e gratuitos, disponíveis no idioma inglês ou português, publicados nos últimos cinco anos (2015-2020), com o foco em UTI pediátrica e epidemiologia. Foram excluídos, na análise integrativa dos artigos aqueles que apresentavam duplicidade em diferentes bases de dados, não estavam disponíveis de forma gratuita e que não abordavam o tema. Devido o fato desse trabalho se tratar de uma pesquisa observacional, do tipo revisão integrativa de estudos já publicados na literatura, dispensou-se a submissão ao comitê de ética em pesquisa em seres humanos, uma vez que as informações utilizadas são secundárias e já foram divulgadas. A pesquisa foi conduzida observando a Resolução 466/12 CONEP-CNS/MS.

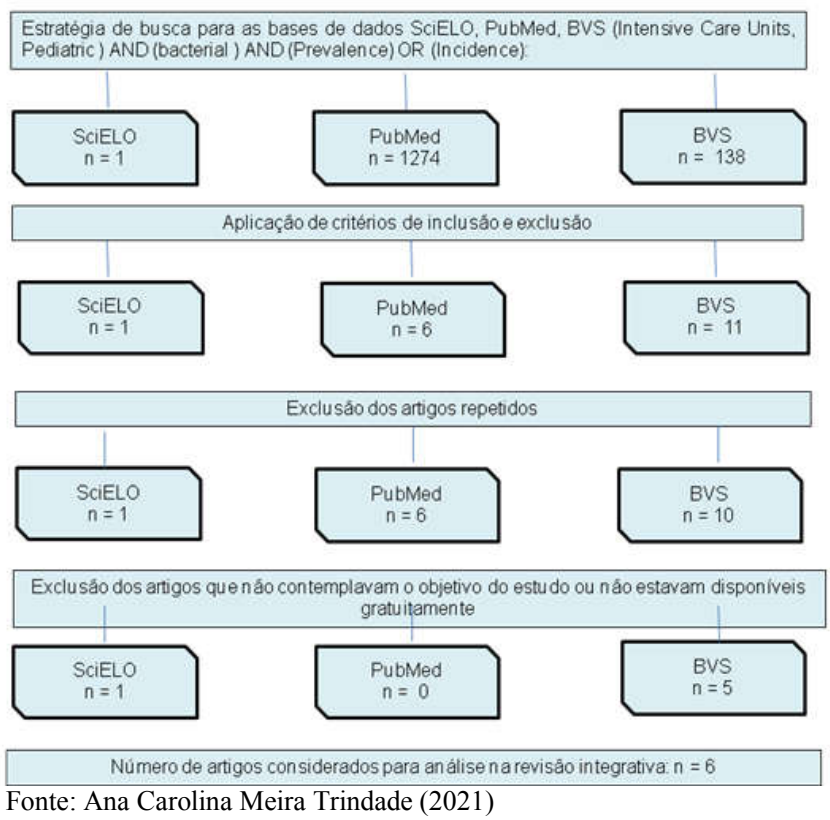

Figura 1. Fluxograma representativo da metodologia de inclusão dos artigos neste estudo

\section{RESULTADOS}

Os resultados dos artigos selecionados que abordavam as bactérias predominantes de infecção hospitalar na UTIP, após a aplicação do filtro e leitura dos títulos e resumos estão explanados na tabela 1 . Com o intuito de complementar as informações trazidas por esses autores, utilizou-se de outros artigos e Portarias a respeito do tema.

\section{DISCUSSÃO}

Fatores de Risco: As infecções hospitalares são consideradas para alguns autores complicações infecciosas de doenças preexistentes e/ou de procedimentos invasivos ou imunossupressores que cursam com a alteração do mecanismo de defesa imunitária do organismo do paciente já debilitado (ZANON, 2009). O paciente internado em uma Unidade de Terapia Intensiva (UTI) já dispõe dos quatro fatores predisponentes de uma infecção: (1) quantidade exacerbada de patógenos em um local; (2) via de acesso ao hospedeiro - acesso venoso central, cateter, intubação orotraqueal; (3) porta de entrada; e (4) susceptibilidade ao hospedeiro. As crianças são mais propensas à infecção hospitalar (IH) devido à lenta maturação do seu sistema imunológico, o compartilhamento de objetos entre pacientes pediátricos, a desnutrição aguda, a presença de anomalias congênitas, o uso de medicamentos, como os corticosteroides, e as doenças hemato-oncológicas (ANVISA, 2006). Ao estudarem os pacientes pediátricos com câncer, Costa e Silva (2015) chegaram à conclusão de que aqueles com câncer hematológico estão mais susceptíveis a adquirir infecção hospitalar, supostamente associada à BGN-MR, principalmente A. baumannii (17\%);S. maltophilia (15\%); Enterobacter spp. (15\%); e Klebsiella pneumoniae (15\%). 
Tabela 1. Distribuição dos artigos selecionados, observando-se os seguintes aspectos: objetivos, metodologia e desfecho do estudo. Fonte: Ana Carolina Meira Trindade (2021).

\begin{tabular}{|c|c|c|c|c|}
\hline AUTOR/ANO & TÍTULO & OBJETIVOS & METODOLOGIA & DESFECHO DO ESTUDO \\
\hline $\begin{array}{l}\text { Moynihan K, Barlow A, Nourse C, } \\
\text { Heney C, Schlebush S, Schlapbach } \\
\text { L. } 2018\end{array}$ & $\begin{array}{l}\text { Severe mycoplasma } \\
\text { pneumoniae infection in } \\
\text { children admitted to } \\
\text { Pediatric Intensive Care }\end{array}$ & $\begin{array}{l}\text { Descrever a incidência, as } \\
\text { características e os resultados de } \\
\text { crianças gravemente doentes com } \\
\text { diagnóstico de infecção confirmada } \\
\text { por M. pneumoniae em } 2 \text { UTIP que } \\
\text { prestam serviços de terapia } \\
\text { intensiva pediátrica no estado de } \\
\text { Queensland, Austrália. }\end{array}$ & $\begin{array}{l}\text { Estudo } \quad \text { de ligação } \\
\text { retrospectivo multicêntrico. }\end{array}$ & $\begin{array}{l}\text { Mycoplasma pneumoniae é uma causa comum de manifestações respiratórias } \\
\text { e extrapulmonares. Aproximadamente } 80 \% \text { dos casos cursam com sintomas } \\
\text { respiratórios com ou sem sepse associada; e } 20 \% \text { teve diagnóstico neurológico } \\
\text { (encefalite e síndrome de Guillain-Barré). A média de idade dos casos } \\
\text { confirmados foi de sete anos. A morte }(6,7 \%) \text { provavelmente não estava } \\
\text { relacionada à infecção, mas com as comorbidades do paciente. A infecção foi } \\
\text { confirmada mais entre crianças com doenças leves à admissão. }\end{array}$ \\
\hline $\begin{array}{l}\text { Brogan T, Thurm C, Hersh A, } \\
\text { Gerber J, Smith M, Shah S, Courter } \\
\text { J, Patel S, Parker S, Kronman M, } \\
\text { Lee B, Newland J. } 2018\end{array}$ & $\begin{array}{l}\text { Variability in Antibiotic } \\
\text { Use Across PICUs }\end{array}$ & $\begin{array}{l}\text { Caracterizar e comparar a } \\
\text { prescrição de antibióticos entre as } \\
\text { UTIPs para avaliar o grau de } \\
\text { variabilidade. }\end{array}$ & $\begin{array}{l}\text { Estudo } \quad \text { multicêntrico } \\
\text { retrospectivo transversal. }\end{array}$ & $\begin{array}{l}\text { Ainda há poucos dados a respeito da diferença da prescrição de antibióticos } \\
\text { entre crianças hospitalizadas na UTIP para as hospitalizadas em enfermarias. } \\
57-79 \% \text { daqueles admitidos em uma UTIP receberam antibióticos, e } 34 \% \\
\text { destes eram agentes de amplo espectro. O uso de antibióticos é influenciado } \\
\text { por um conjunto complexo de variáveis que inclui a gravidade da doença, } \\
\text { patógenos, dados radiográficos e laboratoriais, fatores institucionais e } \\
\text { recomendações baseadas em evidências limitadas. }\end{array}$ \\
\hline $\begin{array}{l}\text { Suwantarat N, Logan L, Carroll K, } \\
\text { Bonomo R, Simner P, Rudin S, } \\
\text { Miltstone A, Tekle T, Ross T, } \\
\text { Tamma P. } 2016\end{array}$ & $\begin{array}{l}\text { The Prevalence and } \\
\text { Molecular Epidemio- } \\
\text { logy of Multidrug- } \\
\text { Resistant Enterobac- } \\
\text { teriaceae Coloniza-tion } \\
\text { in a Pediatric Intensive } \\
\text { Care Unit }\end{array}$ & $\begin{array}{l}\text { Determinar a prevalência e } \\
\text { aquisição de } \beta \text {-lactamases de } \\
\text { espectro estendido (ESBLs), } \\
\text { AmpCs mediados por plasmídeos e } \\
\text { carbapenema-ses colonizando } \\
\text { crianças internadas em uma UTIP. }\end{array}$ & Estudo prospectivo. & $\begin{array}{l}\text { A idade média das crianças admitidas e com infecção bacteriana foi de seis } \\
\text { anos, sendo que } 45 \% \text { eram do sexo feminino. As Enterobacteriaceae MDR } \\
\text { identificadas foram a E. coli, Enterobacter cloacae e espécies de Citrobacter, } \\
\text { K. pneumoniae, Proteus mirabilis e Morganella morganii. O tempo médio para } \\
\text { adquirir a Enterobacteriaceae MDR foi de nove dias. }\end{array}$ \\
\hline $\begin{array}{l}\text { Vijay G, Mandal A, Sankar J, Kapil } \\
\text { A, Lodha R, Kabra S. } 2017\end{array}$ & $\begin{array}{l}\text { Ventilator Associated } \\
\text { Pneumonia in Pediatric } \\
\text { Intensive Care Unit: } \\
\text { Incidence, Risk Factors } \\
\text { and Etiological Agents }\end{array}$ & $\begin{array}{l}\text { Estudar a incidência, etiologia e } \\
\text { fatores de risco associados à } \\
\text { pneumonia associada à ventilação } \\
\text { mecânica (PAVM) em crianças. }\end{array}$ & Estudo de coorte prospectivo. & $\begin{array}{l}\text { O estudo foca nas pneumonias associadas ao ventilador (PAV) que tem como } \\
\text { os bacilos gram-negativos seus principais patógenos. A coleta foi feita por } \\
\text { meio do lavado broncoalveolar (LBA) e demonstrou a presença de } \\
\text { Acinetobacter (47\%), Pseudomonas (28\%), Klebsiella (14\%). }\end{array}$ \\
\hline $\begin{array}{l}\text { Duarte L, Arbo A, Gallardo M, } \\
\text { Riquelme I, Delgadillo L, Jiménez } \\
\text { H. } 2019\end{array}$ & $\begin{array}{l}\text { Factors associated with } \\
\text { vancomycin-resistant } \\
\text { enterococci colonization } \\
\text { in a pediatric intensive } \\
\text { care unit of Paraguay: A } \\
\text { cross-sectional study on } \\
\text { hospital charts }\end{array}$ & $\begin{array}{lccr}\text { Determinar } & \text { os } & \text { fatores de } & \text { risco } \\
\text { associados } & \text { à } & \text { colonização de } \\
\text { enterococo } & \text { resistente dà } \\
\text { vancomicina } & \text { em pacientes } \\
\text { pediátricos internados em UTIP no } \\
\text { período de janeiro de 2012 a junho } \\
\text { de 2013. }\end{array}$ & $\begin{array}{lcc}\text { Estudo } & \text { transversal } & \text { de } \\
\text { prontuários hospitalares. }\end{array}$ & $\begin{array}{l}\text { O artigo foca nos fatores associados à infecção por Enterococos, como idade } \\
(6 \pm 5,7 \text { anos), comorbidades - (doenças hematológicas e tumoração). A } \\
\text { prevalência de transporte de Enterococcus sp resistente à vancomicina na } \\
\text { unidade de terapia intensiva pediátrica foi de } 18,6 \% \text {. }\end{array}$ \\
\hline Costa P, Atta E, Silva A. 2015 & $\begin{array}{l}\text { Infection with } \\
\text { multidrug-resistant } \\
\text { gram-negative bacteria } \\
\text { in a pediatric oncology } \\
\text { intensive care unit: risk } \\
\text { factors and outcomes }\end{array}$ & $\begin{array}{l}\text { Avaliar os preditores e os } \\
\text { desfechos associados às infecções } \\
\text { bacterianas } \quad \text { gram-negativas } \\
\text { multirresistentes (BGN-MR) em } \\
\text { uma UTIP oncológica. }\end{array}$ & Estudo de caso-controle. & $\begin{array}{l}\text { O estudo foca em crianças com câncer e a prevalência de bactérias gram- } \\
\text { negativas multirresistentes (BGN-MR) e não multirresistentes (BGN não MR). } \\
\text { Os patógenos mais frequentes BGN-MR são: } A \text {. baumannii (17\%); S. } \\
\text { maltophilia } \quad(15 \%) ; \text { Enterobacter spp. } \\
\text { pneumoniae (15\%). Os patógenos de ocorrência mais frequente entre os BGN } \\
\text { não MR foram: P. aeruginosa (41\%); A. baumannii }(26 \%) \text {; } \text { K. pneumoniae } \\
(15 \%) \text {. As doenças mais comuns no grupo infectado com BGN-MR foram } \\
\text { tumores no SNC, neuroblastoma, linfoma não-Hodgkin e leucemia } \\
\text { linfoblástica aguda; já a das BGN não MR são tumor de SNC, neuroblastoma, } \\
\text { rabdomiossarcoma e tumor de Wilms. Os tipos mais comuns de infecção em } \\
\text { ordem de frequência foram pneumonia, infecções da corrente sanguínea e do } \\
\text { trato urinário. }\end{array}$ \\
\hline
\end{tabular}


Mello e colaboradores (2009) classificam os fatores de risco por situações, incluindo:

- Pacientes no pós-operatório: assistência médica, proporção de medicamentos invasivos, nutrição parenteral, terapia antimicrobiana e sua duração;

- Infecção da corrente sanguínea: uso do acesso venoso central e de múltiplos cateteres, nutrição parenteral, elevado número de transfusão de hemácias, circulação extracorpórea, duração do uso do cateter arterial, troca do cateter por um fio-guia (cinco vezes maior o risco);

- Infecção das vias aéreas inferiores: medicamentos imunossupressores em uso ou bloqueadores neuromusculares, transporte do paciente para fora da UTIP (aumenta os riscos de pneumonia associada à ventilação mecânica - PAVM), broncoscopia.

A incidência dessas infecções em um Hospital no RJ ocorreu da seguinte forma: na UTIP chegou a $23,6 \%$, já em unidades pediátricas em geral a variação era de um a $2,5 \%$. Isso ocorre pelo excesso de procedimentos invasivos, má higiene das mãos, lapsos em técnicas de assepsia, seleção inadequada de antibióticos, deslocamentos dentro do hospital, doença de base grave, desnutrição e imunossupressão. As consequências se resumem a pneumonia, infecções da corrente sanguínea e do trato urinário (COSTA, ATTA, SILVA, 2015).

Bactérias: As bactérias são seres procarióticos compostos de parede, membrana citoplasmática, citoplasma e núcleo (um cromossomo). Algumas possuem cápsula, mesossomos, flagelos, pili, fimbrias, endósporo e plasmídios. São classificadas em dois grupos por diferenças em sua parede bacteriana (MOREIRA, 2015):

- Bactérias gram-positivas: camada mais espessa de peptideoglicano.

- Bactérias gram-negativas (BGNs): camada mais delgada de peptideoglicano e uma membrana externa com dupla camada de fosfolipídios e o lipopolissacarídeo (LPS) que funciona como antígeno e diferencia as espécies de BGNs. Além disso, contém o lipídeo A (tóxico, é a endotoxina da BGN).

De modo geral, as bactérias gram-positivas mais predominantes são o Enterococcus spp e Staphylococcus aureus. Entretanto, são os bacilos gram-negativos os mais prevalentes em UTIs no Brasil, devido à elevada resistência de antimicrobianos de última geração disponíveis. $\mathrm{O}$ meio de transmissão dos bacilos se dá por contato direto ou indireto. É classificado em dois grandes grupos (ANVISA, 2007):

- Bacilos gram-negativos não fermentadores de glicose: sobrevive em águas e em ambientes com nutrientes que favorecem sua presença no trato respiratório. Seus mecanismos de resistência são: produção de betalactamases, perda de porinas da parede bacteriana, mecanismo de efluxo a partir do ambiente intracelular e modificação do sítio de ligação dos antibióticos. Inclui Pseudomonas aeruginosa e Acinetobacter spp.

- Bacilos gram-negativos fermentadores de glicose: envolvidos em quase todas as infecções respiratórias e urinárias da UTI. Inclui: Enterobacter spp., E.coli, Klebsiella spp., Serratia spp., Citrobacter spp., Proteus spp., e outros.

Um dos motivos para o predomínio dessas bactérias é a menor adesão à higienização das mãos, associada ao excesso de trabalho, risco intrínseco de transmissão de agentes infecciosos entre pacientes e uso excessivo de antimicrobianos (ANVISA, 2007).

Bactérias - Mycoplasma pneumoniae: O M. pneumoniae não possui parede celular, por isso não cora no Gram. Ele cresce em condições aeróbias e anaeróbicas. Seu mecanismo de infecção está relacionado aos efeitos diretos da bactéria, efeitos imunomediados indiretos e os mediados por vasculite ou trombose secundária à citocinas, quimiocinas ou imunomodulação. Possui receptor Toll-like2 e proteínas transmembranas que auxiliam na aderência e deslizamento do patógeno ao longo do epitélio respiratório - pelo qual tem tropismo. Garante sua sobrevivência por meio do parasitismo de superfície de células-alvo, aquisição de precursores biossintéticos e sobrevivência intracelular (VALLEJO, 2020). Moyniham e colaboradores (2017) descrevem que as infecções causadas pelo M. pneumoniae acometem crianças com média de sete anos com manifestações respiratórias e extrapulmonares, sendo que $73 \%$ apresentam pneumonia, $6 \%$ asma, $1 \%$ sepse associado à patologia respiratória. Os $20 \%$ restantes tiveram diagnóstico neurológico - encefalite e síndrome de Guillain-Barré. Uma característica deste estudo foi de que as crianças com doenças leves são mais infectadas que as gravemente enfermas.

Bactérias gram-positivas - enterococos: Os enterococos são cocos gram-positivos, anaeróbios facultativos e incluem as espécies $E$. faecalis e o E. faecium. A espécie do E. faecalis são mais virulentas, podem causar bacteremia, infecções do trato urinário, endocardite e meningite. Além de ter seus isolados mais suscetíveis aos agentes beta-lactâmicos. É um dos principais organismos causadores de infecção hospitalar, principalmente, em pacientes mais graves, com internação prolongada e aumento do uso de antibióticos (MURRAY, MILLER, 2019).

Essas espécies sobrevivem a temperaturas adversas $\left(60^{\circ}\right.$ por 30 minutos), reagem com o anti-soro $\mathrm{D}$, hidrolisam a esculina na presença de bile e resistem a alguns antissépticos. Além disso, são de alta resistência antimicrobiana (vancomicina) (MURRAY, 2019). A sua resistência vem de fatores intrínsecos, como genes potenciais de adesina, capacidade de adquirir novos genes (plasmídeos, transpósons e conjugação) e sofrer mutação. Os enterococos também são resistentes a antibióticos que quase não se usam para o tratamento de infecções enterocócicas, como as tetraciclinas, os macrolideos, a clindamicina, rifampicina e fluoroquinolonas. Isso mostra que as bactérias da flora podem sofrer resistência apenas por coexistir com outras patogênicas, adquirindo os seus genes de resistência (ARIAS, MURRAY, 2019). Duarte e colaboradores (2019) analisaram os fatores associados ao transporte de Enterococos spp resistentes à vancomicina nos pacientes pediátricos e o resultado foi de que o histórico de internação anterior em um ano e a exposição a dois ou mais antibióticos de amplo espectro aumentou o risco seis a 13,5 vezes mais. A média de idade de crianças infectadas foi de $6 \pm 5,7$ anos, sendo mais prevalente nos mais velhos. A distribuição por sexo foi de $52,8 \%$ meninos e $47,1 \%$ meninas. O sítio principal de infecção foi a via retal com $18,6 \%$ de swabs positivos, principalmente, entre os internados em pós-operatórios, dengue e sepse.

Bactérias gram-positivas - estafilococos: Estafilococos são microrganismos gram-positivos, sendo que a staphylococcus aureus é uma das mais patogênicas, é anaeróbia facultativa e produtora de enterotoxinas. Cresce em ambientes com valores de $\mathrm{pH}$ de 4,5 e 9,3, a temperaturas entre $7^{\circ}$ e $46^{\circ}$, resiste a ciclos de congelamento e descongelamento. É uma causa de infecção invasiva - aquela que surge em um local do corpo que é estéril em condições de normalidade. Alguns fatores de risco para que desenvolva a contaminação é a presença de corpo estranho, malignidade, imunodeficiência e diabetes mellittus (KAPLAN, 2019). A S. aureus pode colonizar pele (ferida ou intacta) e narinas de pacientes já hospitalizados, dos profissionais de saúde ou de indivíduos saudáveis que atuarão como um reservatório para a transmissão (KAPLAN, 2020). As manifestações clínicas de sua contaminação variam de uma colonização assintomática, infecção de pele e tecidos moles, a infecção invasiva com risco de vida. É um dos poucos patógenos que podem causar quase todos os tipos de infecção, como osteomielite, artrite séptica, pneumonia necrosante, endocardite infecciosa, bacteremia, infecção por cateter intravascular, infecção por derivação do líquido cefalorraquidiano, sepse e síndrome do choque tóxico (KAPLAN, 2020).

Os mecanismos de resistência da $S$. aureus são mediados pelo gene $m e c A$ responsável por codificar uma proteína de ligação $(P B P 2 a)-$ 
ela permite ao organismo crescer e se dividir na presença de meticilina e outros beta-lactâmicos. Por isso, as cepas se dividem em:

- $\quad$ HA-MRSA ( $S$. aureus resistentes à meticilina adquiridos no hospital): cultura positiva vinda de local estéril com mais de 48 horas após a internação.

- $\quad$ CA-MRSA (S. aureus resistente à meticilina adquiridos na comunidade): suas cepas tem a característica de lisar os neutrófilos (responsável pela defesa celular do hospedeiro contra o patógeno).

Existe uma prevalência de resistência à meticilina, vancomicina e clindamicina. Essa última tem aumentado sua prevalência nas últimas décadas, pelo uso exacerbado desse medicamento para tratar outras infecções na infância. A mesma justificativa pode ser usado para a resistência crescente a fluoroquinolonas e tetraciclinas (FOWLER, SEXTON, KAPLAN, 2019). Um estudo de Brogan e colaboradores (2018) analisou que $12,5 \%$ das crianças em um período de quatro anos tiveram atendimento na UTIP. Destas, $69,5 \%$ receberam pelo menos um dia de antibiótico.

Sendo este número mais elevado nos pacientes em pós-operatório. Foi analisado também que devido à resistência à meticilina, nesse período houve uma diminuição gradativa do uso de agentes de amplo espectro (duas vezes menos) e ativos contra MRSA (três vezes menos) ficando mais restrito para pacientes gravemente doentes, com procedimentos invasivos, instabilidade hemodinâmica e/ou respiratória e sistema imune agudo ou cronicamente afetado com exposição a microrganismos resistentes.

Bactérias gram-negativas - Klebsiella spp: A Klebsiella spp. é um bacilo gram-negativo presente na microbiota intestinal e oral normal. A capacidade de virulência está associada a sua cápsula polissacarídica, ao sistema de captação de ferro, o fenótipo mucóide e o lipopolissacarídeo tóxico. São bactérias que possuem sobrevivência elevada em pele e em ambientes secos (MOREIRA, 2019). Os principais fatores de risco para a infecção são uso prévio de antibióticos e uso de cateteres vesicais, tubos endotraqueais e cateteres intravenosos. Tem sido associada à infecção do trato urinário, infecção pulmonar, bacteremia e outras infecções em indivíduos suscetíveis (YU, CHUANG, 2019).

Costa, Atta e Silva (2015) em estudos analisaram a incidência de bactérias gram-negativas em pacientes pediátricos oncológicos no período de três anos e em 756 admissões na UTIP houve 101 episódios de infecção por BGN e destes 47 (46,5\%) foi por BGN-MR. Entre as BGN-MR predominaram Klebsiella pneumoniae, Enterobacter spp., S. maltophilia e Acinetobacter baumannii. Os pacientes possuíam tumor do sistema nervoso central, neuroblastoma, linfoma não-Hodgkin e leucemia linfoblástica aguda. Os sítios de infecção predominantes foram aspirado traqueal (36,2\%), hemocultura $(8,17 \%)$, cultura de urina $(8,5 \%)$ e cultura da ponta do cateter $(6,4 \%)$, consequentemente, as principais manifestações foram pneumonia, infecção da corrente sanguínea e do trato urinário.

Em contrapartida, Vijay e colaboradores analisaram que em relação à Pneumonia associada ao ventilador (PAV) a Klebsiella pneumoniae foi o terceiro microrganismo mais prevalente (14\%) - Acinetobacter baumannii e Pseudomonas aeruginosa foram o primeiro $(47 \%)$ e segundo (28\%) mais prevalentes, respectivamente.

A Klebsiella pneumoniae KPC tem resistência de até $95 \%$ dos antimicrobianos atuais, um dos seus mecanismos de fuga é:

- $\quad$ A produção de beta-lactamases de espectro estendido (ESBL) não sendo sensíveis às penicilinas, cefalosporinas, aminoglicosídeos e quinolonas.

- Produção de beta-lactamases tipo AmpC: hidroliza cefoxitina (cefalosporina de $3^{\text {a }}$ geração).

- Produção de carbapenemases, como as metalo-betalactamases $(M B L)$.
- Produção de carbapenemases tipo KPC: frequente em imunodeprimidos hospitalizados e/ou com materiais invasivos (cateter, sonda) (MOREIRA, 2011).

Bactérias gram-negativas - Pseudomonas spp: A pseudomonas spp. é um dos principais agentes de infecção nosocomial em hospitais brasileiros. É uma bactéria gram-negativa, unicelular, não formadora de esporos, flagelada, aeróbia e com metabolismo energético respiratório. Pode causar infecção aguda ao produzir toxinas e/ou infecção crônica pela ação de seu biofilme. É um dos principais patógenos respiratórios em pacientes com fibrose cística (doença genética que tem como manifestações clínicas principais à doença pulmonar obstrutiva crônica e a insuficiência pancreática exócrina) (SILVA, et al, 2013).

Neves (2011) A P. aeruginosa estava envolvida em 30,3\% das infecções de corrente sanguínea/cateter, trato respiratório, trato urinário, pele/tecidos moles, e com 36,6\% de resistência ao Imipeném (IPM). Os seus principais mecanismos de resistência ao IPM são:

- $\quad$ Perda de porinas;

- $\quad$ Presença de proteínas de ligação às penicilinas (PBP) com baixa afinidade carbapenêmica;

- Superexpressão de bombas de efluxo - garante uma relativa impermeabilidade a maioria dos antibióticos.

- Hidrólise enzimática.

No Brasil, há a $P$. aeruginosa produtores de metalobelactamase $(M B L)$, grupo responsável pela resistência aos carbapenêmicos. No estudo de Costa, Atta e Silva (2015) entre os patógenos mais frequentes de BGN não MR a $P$. aeruginosa é o principal (41\%), seguida por A. baumanii (26\%) e K. pneumoniae (15\%).

Bactérias gram-negativas - Acinetobacter baumannii: $A$. baumannii é um cocobacilo gram-negativo, imóveis, aeróbios, catalase-positivos e oxidase-negativos com capacidade de acumular mecanismos de resistência gerando cepas resistentes aos antibióticos disponíveis no mercado. Pode colonizar a pele, feridas e os tratos respiratório e gastrointestinal. A maioria de informações associada aos cuidados de saúde é baseada em investigação de surtos com posterior estabelecimento de uma cepa endêmica predominando (KANAFANI, KANI, 2020).

Os estudos de Vijay (2018) e Kanafani, Kani (2020) concordam que entre as crianças no meio hospitalar a infecção por $A$. baumannii está associada naquelas internadas há mais tempo e com necessidade de ventilação mecânica. Sendo, portanto, a principal causa de pneumonia nesses pacientes (47\%) com confirmação por meio do aspirado traqueal e hemocultura.

Os principais mecanismos patogênicos são:

- $\quad$ Formação de biofilme;

- Produção da proteína $\mathrm{A}$ da membrana externa (OmpA): auxilia a formação do biofilme e da apoptose celular.

- Cápsula K1: cápsula de polissacarídeo para prevenir a ativação do complemento e reduzir a fagocitose.

- Sistema de aquisição de ferro mediado por sideróforo: sobrevive a condições de deficiência de ferro.

- Fímbrias: ajudam na fixação do organismo às superfícies ambientais e na colonização de superfícies bióticas células epiteliais brônquicas.

Bactérias gram-negativas - Stenotrophomonas maltophilia: A $S$. maltophilia é um bacilo gram-negativo, aeróbio, não fermentativo e intimamente relacionado à espécie Pseudomonas. Possui mecanismos de resistência intrínsecos ou adquiridos (LEWIS, ZAAS, 2020):

- Resistência a beta-lactamases: devido à penicilinase contendo zinco (L1) e a cefalosporinase (L2) 
- Resistência à aminoglicosídeos: devido à acetil-transferase e mudanças dependentes da temperatura na estrutura do lipopolissacarídeo da membrana externa (LPS)

- Bombas de efluxo: conferem maior resistência a várias classes de antibacterianos.

É um dos patógenos multirresistentes mais prevalentes entre os pacientes oncológicos, tendo o aparelho respiratório como sítio mais comum, seguido pelo trato urinário e cateter venoso central (COSTA, ATTA, SILVA, 2015).

\section{CONCLUSÃO}

Por meio deste estudo de revisão foi possível identificar que há uma predominância de bactérias gram-negativas, principalmente, com multirressistência e que existem associações entre procedimentos, tempo de internamento e/ou situações de saúde e bactérias mais prováveis de contaminarem o paciente pediátrico. É importante ressaltar que as limitações desta pesquisa estão relacionadas à inexistência de artigos abordando o tema de forma objetiva, mas sempre comparando às bactérias em relação a uma doença ou sítio. Além disso, algumas publicações não estavam disponíveis de forma gratuita, o que impediu a sua captura e análise.

\section{REFERÊNCIAS}

Agência Nacional DE Vigilância Sanitária. Investigação e Controle de Bactérias Multirresistentes. Brasília, 2007.

Agência Nacional DE Saúde Suplementar. Ministério da Saúde. Média de Permanência UTI Pediátrica. Brasília, 2013.

Agência Nacional DE Vigilância Sanitária. Pediatria: prevenção e controle de infecção hospitalar. Brasília, 2006.

Andrade, L. N.; Darini, A. L. C. Bacilos gram-negativos produtores de beta-lactamases: que bla bla bla é esse? Journal of Infection Control. Brasília, v. 6, n.1, p. 16-25, jan./mar. 2017.

Arias, C. A.; Murray, B. E. Mechanisms of antibiotic resistance in enterococci. UpToDate, março 2019.

Brasil. Resolução $n^{\circ} 7$, de 24 de fevereiro de 2010. Dispõe sobre os requisitos mínimos para funcionamento de Unidades de Terapia Intensiva e dá outras providências. Brasília, 2010.

Costa, Graziela DE Araujo. Comparação entre dois escores de prognóstico (Prism e Pim) em unidade de terapia intensiva pediátrica. Dissertação (Mestrado em Ciências) - Faculdade de Medicina da Universidade de São Paulo, São Paulo, 2011.

Costa, P. O.; Atta, E. H.; Silva, A. R. A. da. Infecção por bactérias gram-negativas multirresistentes em uma unidade de terapia intensiva pediátrica oncológica: fatores de risco e resultados. Jornal de Pediatria, Porto Alegre, v. 91 n. 5, outubro 2015.

Couto, R. C. et al. Infecção Hospitalar e outras complicações não infecciosas. 4. ed. Brasil: Grupo Gen, 2009.

Duarte, L. et al. Factors associated with vancomycin-resistant enterococci colonization in a pediatric intensive care unit of Paraguay: A cross-sectional study on hospital charts. PubMed, setembro 2019.

Fowler, V. G. Jr; Sexton, D. J.; Kaplan, S. L. Staphylococcus aureus bacteremia in children: Epidemiology and clinical features. UpToDate, maio 2019.

Gama, Z. A. S. da et al. Desenvolvimento e validação de indicadores de boas práticas de segurança do paciente: Projeto ISEP-Brasil. Caderno Saúde Pública. Rio de Janeiro, v. 32, n. 9, 2016.

Gil, Costa, A. Como Elaborar Projetos de Pesquisa. 4. ed. São Paulo: Atlas, 2002

Júnior, Marçal Durval Siqueira Paiva. Fatores associados ao tempo para o surgimento de bactérias Gram-negativas multidroga resistentes em pacientes críticos: um Estudo Prospectivo.
Dissertação (Mestrado em Medicina Tropical) - Centro de Ciências da Saúde da Universidade Federal de Pernambuco, Recife, 2012.

Kanafani, Z. A.; Kani, S. S. Acinetobacter infection: Epidemiology, microbiology, pathogenesis, clinical features, and diagnosis. UpToDate, maio 2020

Kaplan, Sheldon L. Methicillin-resistant Staphylococcus aureus infections in children: Epidemiology and clinical spectrum. UpToDate, agosto 2019.

Kaplan, Sheldon, L. Staphylococcus aureus in children: Overview of treatment of invasive infections. UpToDate, abril 2020.

Leoncio, J. M. et al. Impacto das infecções relacionadas à assistência à saúde nos custos da hospitalização de crianças. Revista da Escola de Enfermagem da USP. São Paulo, v. 53, agosto 2019

Lewis, S. S.; ZAAS, A. Stenotrophomonas maltophilia. UpToDate, outubro 2020

Mello, M. J. G. de et al. Risk factors for healthcare-associated infection in pediatric intensive care units: a systematic review. Caderno de Saúde Pública. Rio de Janeiro, v. 25, 2009.

Moreira, V. C.; Freire, D. Klebsiella pneumoniae e sua resistência à antibióticos. Disponível em: <http://www.cpgls.pucgoias.edu.br/ 6mostra/artigos/SAUDE/VANESSA\%20CARVALHO\%20MOR EIRA.pdf $>$. Acesso em: 25 nov. 2019.

Moreira, J. L. B.; Carvalho, C. B. M. de; Frota, C. C. Visualização bacteriana e colorações. Fortaleza: Imprensa Universitária, 2015.

Moynihan, K. M. et al. Severe Mycoplasma pneumoniae Infection in children admitted to Pediatric Intensive Care. The Pediatric Infectious Disease Journal. Philadelphia, v. 37, n. 12, dezembro 2018.

Murray, Barbara E. Microbiologia dos enterococos. Microbiology of enterococci. UpToDate, março 2019.

Murray, B. E.; Miller, W. R. Treatment of enterococcal infections. UpToDate, novembro 2019.

Neves, P. R. et al. Pseudomonas aeruginosa multirresistente: um problema endêmico no Brasil. Jornal Brasileiro de Patologia Medicina Laboratorial. Rio de Janeiro, v. 47, n. 4, p. 409-420, agosto 2011.

Rang, H.P. et al. Farmacologia. $7^{\mathrm{a}}$ ed. Rio de Janeiro: Futura, 2011.

Silva Filho, L. V. R. F. da. et al. Infecção por Pseudomonas aeruginosa em pacientes com fibrose cística: evidências científicas sobre o impacto clínico, diagnóstico e tratamento. Jornal Brasileiro de Pneumologia. Brasília, v. 39, n. 4, p.495-512, fevereiro 2013

Suwantarat, N. et al. The Prevalence and Molecular Epidemiology of MultidrugResistant Enterobacteriaceae Colonization in a Pediatric Intensive Care Unit. Infect Control Hospital Epidemiology. Cambdridge, v. 37, n. 5, p. 535-543, maio 2016

Tavares, W. Antibióticos e quimioterápicos para o clínico. 3. ed. São Paulo: Atheneu, 2014.

Torre, F. P. F. La; Baldanzi, G.; Troster, E. J. Fatores de risco para infecções da corrente sanguínea relacionadas a cateter em unidades de terapia intensiva pediátrica. Revista Brasileira Terapia Intensiva, 2018.

Vallejo, J. G. Mycoplasma pneumoniae infection in children. UpToDate, fevereiro 2020.

Vijay, G. et al. Ventilator Associated Pneumonia in Pediatric Intensive Care Unit: Incidence, Risk Factors and Etiological Agents. The Indian Journal of Pediatrics. New Delhi, v. 85, n. 10, p. 861-866, outubro 2018.

$\mathrm{Yu}$, W.; Chuang, Y. Clinical features, diagnosis, and treatment of Klebsiella pneumoniae infection. UpToDate, abril 2019.

Zanon, U. Etiopatologia das Complicações Infecciosas Hospitalares. In: COUTO, R. C. et al. Infecção Hospitalar e outras complicações não-infecciosas da doença: epidemiologia, controle e tratamento. $4^{\text {a }}$ Ed. Rio de Janeiro: Guanabara Koogan, 2009. 